\title{
Teaching Design of Network Course Based on Blended Learning Theory-- Taking Foreign Architectural History as an Example
}

\author{
Bo ZHOU, Jia-Hao LIU, Yi-Ge XIAO, Wen-Hua JIANG
}

School of urban construction, Jiangxi Normal University, Nanchang, Jiangxi ,China,330022

524170946@qq.com

Keywords: blended teaching; "history of foreign architecture"; web based course; instructional design

\begin{abstract}
Based on the present situation of network courses in Colleges and universities and the teaching achievements of the "history of foreign architecture", this paper mainly discusses the teaching design of "foreign architecture history" from the angle of mixed teaching theory, and further ponders and sums up the teaching methods of "foreign architecture history" in the network course. The purpose of this study is to integrate the rich network resources with the traditional educational model, and to combine the teaching and learning with the school network course as a platform to improve the overall quality of teaching.
\end{abstract}

\section{Introduction}

In twenty-first Century, the development of network technology has become an important factor affecting curriculum development. The construction of web-based courses has become a major issue in the field of education ${ }^{[1]}$. The interactive, timeliness and global characteristics of network courses, as well as the new learning methods of space-time separation between teachers and students, provide students with a large number of convenient learning opportunities, excellent teaching environment and rich teaching resources, so that the learning activities are more autonomous and individualized, so that the adaptability of education is greatly strengthened. The course of "history of foreign architecture" is a cross course which combines architecture, planning, garden and art. It occupies an important position in the professional curriculum system. Its main purpose is to expand knowledge, improve cultural accomplishment, understand the law of architecture development, learn excellent design techniques and cultivate aesthetic ability. The origin of the theory of architecture ${ }^{[2]}$.Under the new situation of information teaching mode, how to use the network platform to improve the teaching method of "the history of foreign architecture" so as to improve the teaching quality is one of the problems to be solved in the course of the "foreign architectural history" course. This paper combines the teaching construction practice of the "foreign architecture history" network course and advances the implementation process. We hope to provide reference and reference for the teaching design of the course.

\section{The Proposal of the Blended Teaching Theory}

At present, domestic scholars define Blending Learning from the perspective of school education and teaching ${ }^{[3]}$.Professor He Kekang believes that the so-called "blending learning" is the combination of the advantages of traditional teaching methods and the advantages of network teaching and learning. It not only plays the leading role of teachers' guidance, 
enlightening and monitoring the teaching process, but also fully embodies the initiative, enthusiasm and creativity of the students as the subject of the learning process ${ }^{[4]}$.Professor $\mathrm{Li}$ Jia Hou translated BlendingLearning into "integrated learning", referring to the optimization and combination of all the teaching elements in order to achieve the goal of teaching ${ }^{[5]}$.The author thinks that the mixed teaching is to integrate the network teaching resources with the traditional classroom teaching in order to meet the learning needs of different students and realize the systematization, integrity and optimization of the course teaching by using the teachers as the guidance and motivate the students' self-study as the motive force and adopt the corresponding teaching techniques and methods.

Traditional teaching makes use of teachers' professional experience, body language and enthusiasm to create a good learning environment, mobilizing the enthusiasm and participation of the students. At the same time, teachers can effectively monitor the whole teaching process and complete the teaching goals and tasks. But the traditional teaching of "foreign architectural history" is similar to the teaching of history, which introduces the development of architecture in the world in a series of ways based on time and place.Its related background is unfollower, which greatly restricts the students' overall understanding of the history of architecture. In addition, students lack the experience and experience of foreign architecture. The communication time between teachers and students is less, and the students' initiative and creativity are limited. In contrast, although network teaching can provide a flexible resource platform for students, it can better cultivate students' ability to learn independently, but there is less emotional communication between teachers and students, lack of active teaching environment and on-the-spot guidance. Based on the two kinds of teaching analysis, we can neither completely break away from the traditional classroom teaching, nor adopt the digital network teaching, and the combination of the two can effectively combine the two teaching modes, which can make the students build their own knowledge structure under the good communication situation, which not only conforms to the present design specialty. It is also an effective way to improve the teaching quality by observing the reality and gradually linking up with the network information resources ${ }^{[6]}$.

\section{The teaching design of the network course in blended teaching}

In the teaching model of the mixed network curriculum, teachers play more roles as learning help, knowledge imparting and after-school organizers, as well as interactive communicators providing learning resources. The author intends to combine the characteristics of the "history of foreign architecture" with three aspects of the content module, including the integration and design of teaching content, the driving of teaching task, the construction and design of the teaching environment, and the systematic teaching design and discussion.

\section{Integration and design of teaching content}

Division of ancient and modern times. The history of foreign architectural history is divided into the history of Foreign Architecture (before the end of nineteenth Century) and the history of modern architectural history in other countries. In the assignment of class hours, the proportion of the ancient and modern times should be grasped and adjusted, and the proportion of the teaching materials should not be completely determined according to the content of the contents or the teachers' interest and the scope of knowledge, but the proportion of each part should be properly adjusted according to the teaching reform ${ }^{[7]}$.In the ancient part, the direct 
guidance of professional courses is less. Students only need to understand the development law and evolution process of the history of architecture. Therefore, teachers can guide demonstration in the classroom, use the network platform to upload notes, students use the network to learn independently after class. In the modern part, we should not only understand the law of the development of architecture, but also need to understand the design process of the building and the influence of the architecture itself. It not only requires more classroom communication time, but also needs to expand the relevant architectural knowledge. Therefore, teachers should introduce the content frame in the classroom and use the network teaching in the classroom. Platform upload requires expanded content, so that students can independently learn and learn architectural knowledge.

Construction and integration of the content of resources. In order to promote the good construction of students' knowledge, the design and development of resource content should be shifted from "teaching mainly" to "equal importance to teaching and learning", that is, not only to develop materials and courseware resources, but also to develop resources to support independent inquiry, cooperative communication and research study ${ }^{[8]}$. The development of architecture is bound to have a direct connection with the social background and religious culture at that time. In order to understand the course of the development and evolution of the architecture, it is necessary to have a certain understanding of the social background at that time.So in the course of teaching, in addition to imparting architectural knowledge itself, teachers need to analyze history, humanities and customs to help students understand the history of architecture better. However, the relevant knowledge is like the sea. It is difficult for students to extract what they need in a short time, but not to talk about the integration of their knowledge. For this reason, teachers can link and refine them, establish effective resources, and learn background knowledge under the framework of the content of the teachers. The knowledge structure of the body combines it effectively with the course content of "foreign architectural history".

In line with professional information and hot spots. The development of world architecture is a trend of diversification and complexity, and it has gradually become the mainstream of architectural design in the world, the focus of debate in architectural critics and the excitement of the attention of architectural students ${ }^{[9]}$. The characteristic of "the history of foreign architecture" is that some architects are still active in the contemporary architecture stage, and are constantly concerned by the professionals, and become the hot spots in the architectural field.In the course of teaching, actively combining the focus and focus of Architectural Specialty can better stimulate students' professional enthusiasm, study interest, initiative and creativity, and even improve their professional design ability to a great extent. Therefore, in the classroom teaching hot spot information and stimulate the enthusiasm of learning, after class effective use of network teaching platform, let students learn to understand the professional information in depth, and improve their professional learning ability.

\section{The driving of teaching task}

The network teaching platform is used effectively, the teaching tasks are arranged regularly for the students, and they are urged to carry out the teaching task actively in the network environment without the supervision of teachers.

Classical architecture analysis. The classic architecture has a lasting vitality and eternal reference significance. The discussion of the "process of formation of form" in classical 
architecture can reveal the development law of architecture in history, and can also provide useful reference for the development of contemporary and future architecture ${ }^{[10]}$.

Field experience and research and discussion. The course of "history of foreign architecture" is difficult to make students feel the needs of the books on the ground. However, we can examine the local architectural works affected by foreign style, and let the students compare the types of foreign architecture and local architecture in the same period by research. Finally, the hand-painted architecture is made. Figure or practice report is used to show the results on the network platform and conduct classroom discussion and analysis.

\section{The Construction and Design of the Teaching Environment}

In accordance with the required learning goals and tasks, teachers create a good teaching environment for students, so that students can learn the knowledge of the textbook more deeply in a specific theme environment.

Create classroom teaching situation. In the classroom teaching, in addition to the commonly used pictures, it can also combine rich network links and dynamic images to let students feel the architectural situation more truly through images, sounds and animations, and more comprehensive understanding of architectural information and knowledge. For example, for the Renaissance architecture, students can watch the Michelangelo documentary under the teacher's organization. While enjoying and evaluating the art works and the sculpture art, the students can understand the architectural background and the architectural works at the time, so that the students have more detailed feelings about the space, shape, structure and details of the building.

Create network teaching environment. The new building renewal is faster, need to timely supplement new knowledge to meet students' curiosity, so as to create a vigorous vitality of the classroom atmosphere. Teachers can supplement some of the outstanding architects and architectural works that emerge from the teaching materials, for example, the architectural style of Wang Shu, the first architect of the Pulitzer prize winning architectural Pulitzer prize in China in 2012. . In this way, the way to expand the new knowledge can create a good learning interest and atmosphere, and transform the static learning task into a dynamic learning process, and let the students expand their field of vision to the whole architectural field.

\section{The Design of the Module Structure of the Network Course}

According to the above mixed teaching network course design, the author has designed the history of foreign architecture.The network course system is divided into three modules. First, the "course content" module. This part has teaching objectives, teaching syllabus, teaching content, teaching bibliography and literature. It mainly focuses on the content of the teaching materials to extract the key information, and provides the reference books and documents closely following the teaching materials so as to facilitate the students to learn independently. Second, "learning resources" module. This part mainly provides network resources linked to the curriculum, such as video, library, thematic recommendation and professional information, and students can expand their learning independently to help build their own knowledge system. Third, "teaching activities" module. This part is to carry out the pictures, models and practice reports completed during the teaching period. While the students are watching each other, the teachers can also participate in the evaluation or organize the topic discussion, and extend the classroom content to the after-school study so as to better drive the students' self-learning consciousness. 


\section{Conclusions}

In a word, giving full play to the guiding role of traditional teaching teachers and giving full play to the active spirit of students' active learning in the network course make up for the shortcomings of the traditional teaching and network teaching. The enthusiasm of the students to learn "the history of foreign architecture" is aroused by the mixed teaching method, so that the history of pure theory is more practical and can be made more practical. So that students can truly understand the good teaching effect of classroom teaching theory in line with network information in the teaching process.

\section{Acknowledgment}

Project fund: Jiangxi Education Science 13th Five-Year plan (2018), general subject, Practice and research of SPOC teaching mode in Colleges and Universities Based on Blended Learning Theory -- taking foreign architectural history course as an example (18YB023).

\section{Reference:}

[1] Zhong Qiquan, Zhang Hua. World Curriculum Reform Trend [M]. Beijing: Beijing Normal University Press, 2016.

[2] Liu Xian Ju. The teaching way of the history of Foreign Architecture -- Thinking on cross culture teaching and research [J]. Southern architecture, 2015 (1): 28 - 29.

[3] Yu Shumei, Lu Meiyu. The Concept, Level and Application of Mixed Learning [J]. Software Guide, 2007 (7): 18-20.

[4] Ho Chi. The new development of educational technology theory from BlendingLearning: [J]. Electrical education research, 2004 (3): 1-6.

[5] Li Jia thick. On the definition and translation of "BlendedLean1iIlg" and translation [EB / OL]. (2010-06- 06) [2013-06-20].Http: //www.jeast.net /Jiahou / Archi Ves /000618.htm.

[6] Duan Jin, Journal of Ningbo Institute of Engineering, 2012 (2): 83-85.

[7] Liu Xianjue. Discussing the Way of Teaching Foreign Architectural History [J] Teaching Reform Research, 2009 (11): 66-71.

[8]Ho Chi Kang. The problem of educational resources construction and its countermeasures[EB/OL].(2005-07-09)[2013-06-18].Http://www.edu.cn/20031126/3094951.s html.

[9] Liu Songfu. Sectional Interpretation - Teaching Essay of Foreign Architectural History

[J] Central China Architecture, 2006 (6): 127-129.

[10] Han Linfei. The creativity of architects and the cultivation of artistic quality [C] //.2003 Architecture Education International Forum at the Southeast University Architecture School: Regionalism in the context of globalization. Nanjing: Southeast University press, 2005. 